\title{
Spreading behavior of a distilled water droplet on superhydrophobic surface
}

\author{
Dmitry V. Feoktistov, Evgeniya G. Orlova and Anastasia G. Islamova \\ Thermal Theory and Engineering Department, National Research Tomsk Polytechnic University, \\ 634050, Tomsk, Russia
}

\begin{abstract}
The investigation of dynamic contact angle between distilled water droplet and superhydrophobic surface was conducted experimentally. To obtain the values of contact angle during spreading, shadow method was implemented. We used Schlieren method to control the droplet symmetry. The droplet was formed on the surface by syringe pump using nontraditional bottom-up methodology. The drop growth rate was varied by the syringe pump from $0.005 \mathrm{ml} / \mathrm{s}$ to $0.32 \mathrm{ml} / \mathrm{s}$. DCA versus drop volume was obtained for different values of the drop growth rate. Some features of spreading on superhydrophobic surface were pointed out. Interestingly, that the dynamic contact angle increases during all stages previously selected for copper substrates ( 1 - droplet formation; 2 - spreading; 3 formation of the equilibrium contact angle). However, at the droplet growth rate $0.005 \mathrm{ml} / \mathrm{s}$ we found decrease in the contact angle. The droplet was found to take a shape close to a spherical cap in the range of the drop growth rate $0.005 \mathrm{ml} / \mathrm{s}-0.16 \mathrm{ml} / \mathrm{s}$. At higher rates $(0.32 \mathrm{ml} / \mathrm{s}$ and higher) liquid splashing was observed.
\end{abstract}

\section{Introduction}

Spreading of liquid droplet on a solid substrate is a general process in technology and nature. However, despite much research of interface in "solid-liquid-gas" system over many years, the precise nature of three phase contact line at the dynamic interaction of a droplet with a solid surface remains only partially understood. It leads to inhibition of technology development at cooling surfaces [1], various coatings [2], ink jet printing [3,4], spraying fuel in internal combustion engines [5] and etc.

Currently the study of superhydrophobic surfaces has a great interest because of their unique properties and various important applications. By a common definition, a surface is superhydrophobic if the contact angle (CA) of water is larger than $150^{\circ}$ and water droplets readily slide off the surface if the surface is tilted slightly [6]. Applications of superhydrophobic surfaces include self-cleaning and non-wetting coatings and fabrics [7], as well as anti-fogging [8], anti-icing [9], and drag-reducing [10] coatings. A famous example of surface for superhydrophobicity from nature, the lotus leaf, has 10micron papillae in combination with a nanostructure created by hydrophobic wax crystals.

The process of water droplet and solid substrate contacting is characterized by two main parameters: dynamic contact angle (DCA) and three-phase contact line speed. Depending on the threephase contact line speed low-rate dynamic contact angles and high-rate dynamic contact angles are separated. Experimental investigation of DCA change during surface wetting by advancing and receding droplets at slow movement of the three-phase contact line (from 0.002 to $0.09 \mathrm{~mm} / \mathrm{s}$ ) were conducted in [11, 12]. However, wetting dynamics at high three-phase contact line speed (greater than $1 \mathrm{~mm} / \mathrm{s}$ ) [13] remains poorly explored. It is due to that the recording of physical mechanisms of fast 
processes become possible only in the last decade in connection with the improvement of photos and video equipment.

The results of investigating DCA at distilled water droplet spreading on superhydrophobic surface are presented in this paper.

\section{Research method}

The researches have been conducted using experimental setup, shown in Figure 1. It consists of equipment for shadow and Schlieren methods implementation [14].

In shadow optical method light source 1, ground glass 2, transparent shield with an opening 3 and lens 4 are used to produce a beam of plane-parallel light illuminating the droplet on the substrate. The collimating lens 6 and objective of camera 8 are used to project the image on the camera sensor. Transparent shield with an opening 7 is set to reduce the effect of external light sources on measurement.

In Schlieren method source of incoherent light 17, ground glass 16 and coding filter 15 are used to produce the light flux with a stepped intensity decrease in space. A beam of light from the source 17 passed through the collimating lens 14 which transformed it into a plane-parallel. Then it was reflected from the beam splitter 13, fell on the substrate and passed to the lens 12 and projected on a sensor of high-speed video camera 10.

Photographing and video recording of droplet spreading on the surface was carried out simultaneously in two coordinate directions. The equipment for Schlieren method implementation was used to control the droplet symmetry.

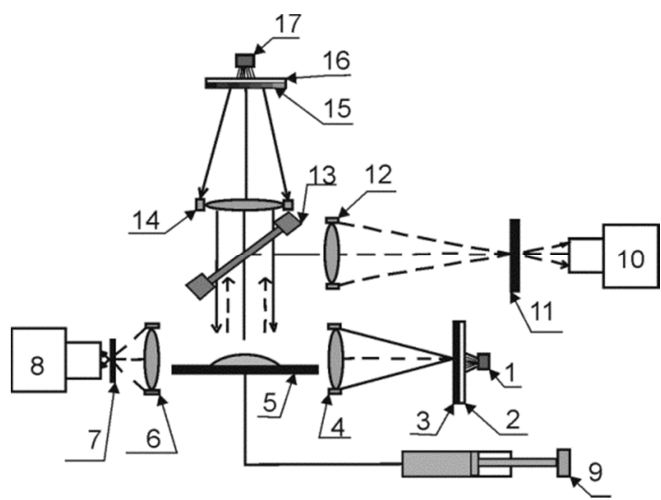

(a)

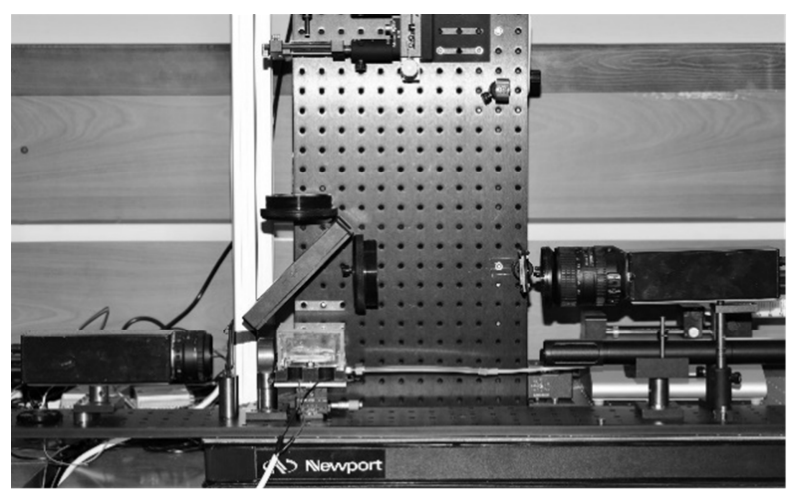

(b)

Figure 1. Schematic diagram (a) and general view (b) of experimental setup: 1, 17 - light source; 2, 16- ground glass; 3, 7, 11 - transparent shield with an opening; 4, 14 - collimating lens; 5- substrate; 6 - condensing lens; 9 - syringe pump; 8, 10 - high-speed video camera; 12 - Schlieren lens; 13 - beam splitter; 15 - coding filter.

The droplet was formed on the surface by the syringe pump 9 (Cole-Parmer Touch Screen). The nondeaerated distilled water was squeezed on the surface through the channel in the substrate. This bottom-up methodology of droplet formation in comparison with the known syringe dispenser facilitates precise control of droplet formation and size as well as it allows reducing the error and maintaining the initial volume. The droplet volume $(0.3 \mathrm{ml})$ and the droplet growth rate (from 0.005 $\mathrm{ml} / \mathrm{s}$ to $0.32 \mathrm{ml} / \mathrm{s}$ with an increase of twice the value on each step) were controlled during the experiment.

The substrate with superhydrophobic surface coating was used at droplet spreading. The substrate is a square thin plate $(50 \times 50 \mathrm{~mm})$ with the opening in the middle with diameter of $1 \mathrm{~mm}$ for liquid squeezing.

\section{Results and conclusions}

The dependence of DCA on the droplet volume at different droplet growth rate is shown in Figure 2. 


\section{TSOTR 2015}

The advancing DCA characterizes a degree of surface wettability to the rate of three-phase contact line moving (at the contact area increasing). According to the experimental results, some features of spreading process on superhydrophobic surface were pointed out. During formation of a liquid droplet the first stage is described by an "abrupt" increase in the three-phase contact line speed and DCA. The second stage of spreading is characterized by a decrease in the three-phase contact line speed and monotonic increase in the advancing DCA.

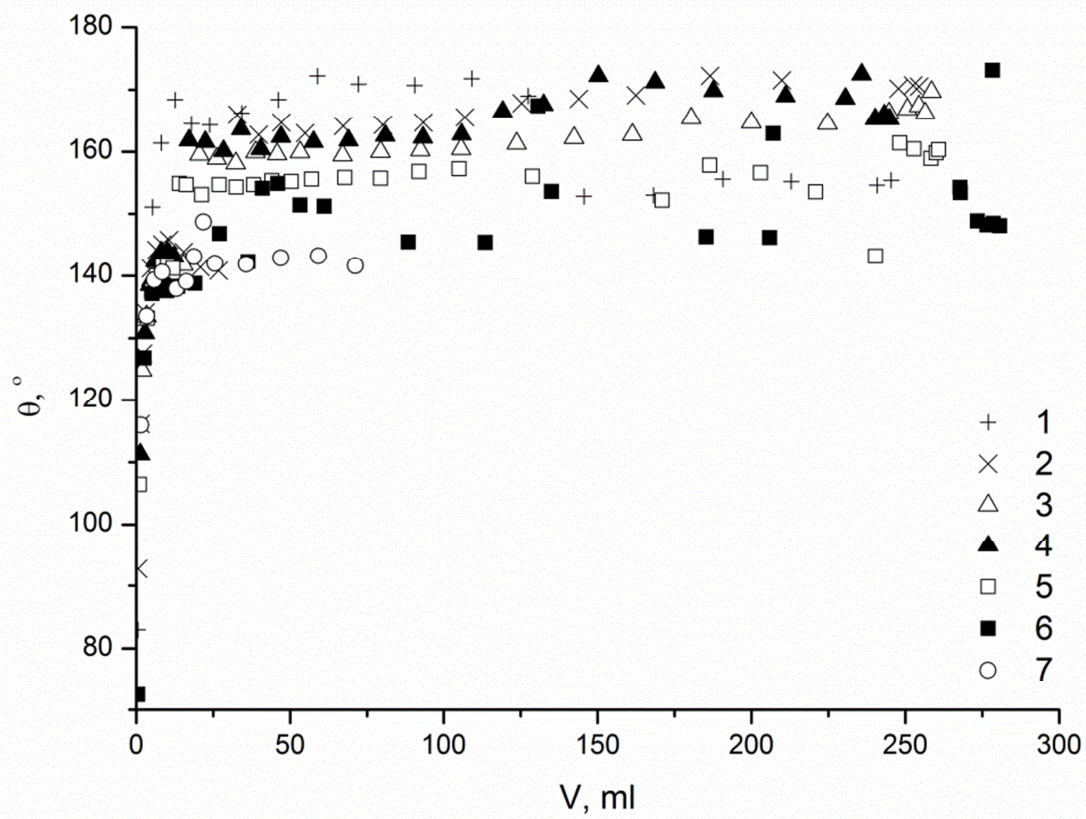

Figure 2. DCA versus droplet volume at different droplet growth rate: $1-0.005 \mathrm{ml} / \mathrm{s}, 2-0.01 \mathrm{ml} / \mathrm{s}, 3-0.02$ $\mathrm{ml} / \mathrm{s}, 4-0.04 \mathrm{ml} / \mathrm{s}, 5-0.08 \mathrm{ml} / \mathrm{s}, 6-0.16 \mathrm{ml} / \mathrm{s}, 7-0.32 \mathrm{ml} / \mathrm{s}$.

During droplet spreading on the superhydrophobic surface the advancing DCA increases during all three stages separated for copper substrates ( 1 - droplet formation; 2 - spreading; 3 - formation of the equilibrium contact angle [15]). The only exception is spreading at the droplet growth rate $0.005 \mathrm{ml} / \mathrm{s}$. Decreasing DCA is indicated during spreading and formation of the equilibrium contact angle stages. Increasing DCA is the reason for that cohesive forces dominate over adhesive at the spreading of distilled water on non-wetting surface (in this case a superhydrophobic). After turning off the syringe pump droplet tends to assume an equilibrium state. Interfacial energy on the "solid - liquid" boundary seeks to squeeze a droplet, notably the surface energy decreases due to the decrease in surface area. The cohesive forces acting inside the droplet prevent spreading.

Within the range of the droplet growth rate from $0.005 \mathrm{ml} / \mathrm{s}$ to $0.16 \mathrm{ml} / \mathrm{s}$, the droplet takes a shape close to a spherical cap. However, at the droplet growth rate $0.32 \mathrm{ml} / \mathrm{s}$ the droplet was not obtained. A significant liquid splashing was observed (Figure 3).

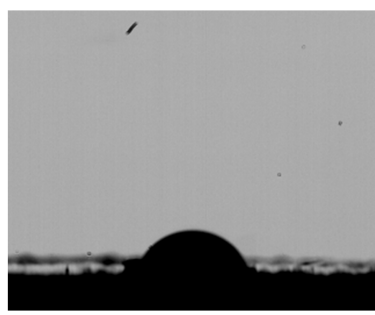

175 frame / $0.016 \mathrm{~s}$

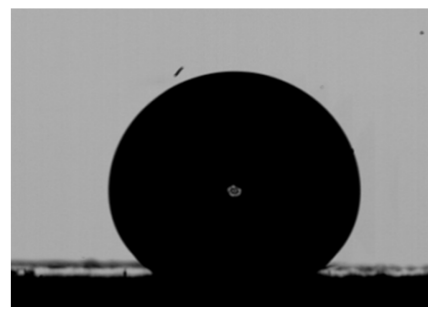

275 frame / $0.141 \mathrm{~s}$

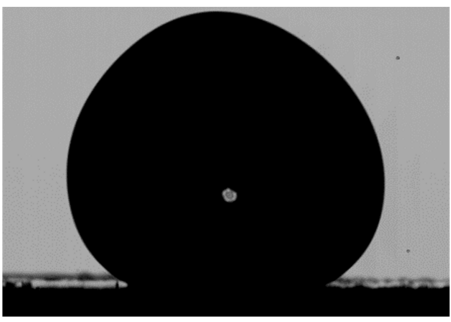

370 frame $/ 0.289 \mathrm{~s}$ 


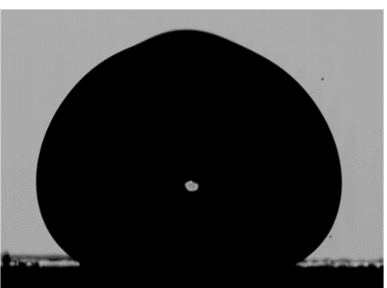

450 frame / $0.414 \mathrm{~s}$

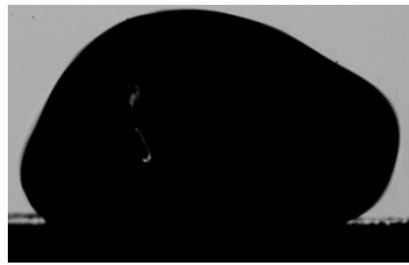

700 frame / $0.805 \mathrm{~s}$

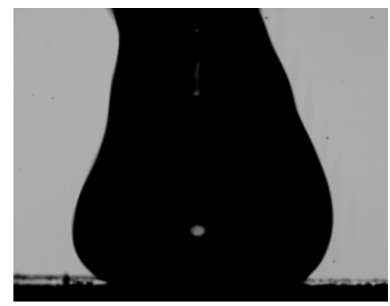

520 frame / $0.523 \mathrm{~s}$

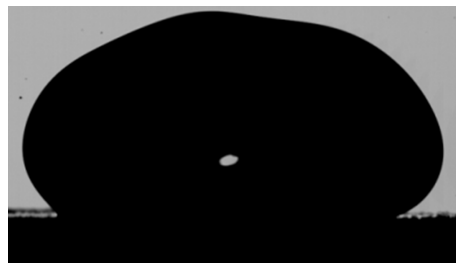

800 frame / $0.961 \mathrm{~s}$

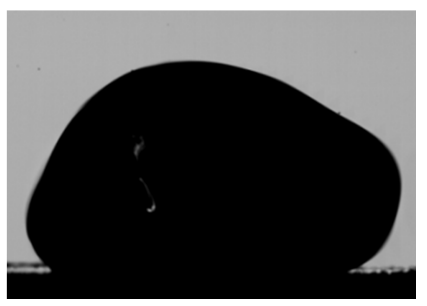

550 frame / $0.570 \mathrm{~s}$

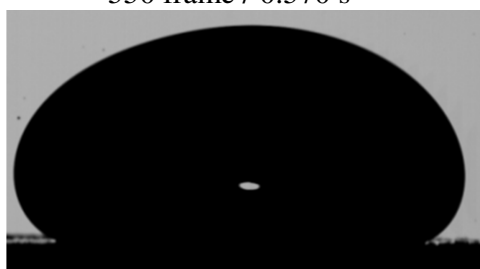

1000 frame / $1.117 \mathrm{~s}$

Figure 3. Evolution of droplet profile at the droplet growth rate $0.32 \mathrm{ml} / \mathrm{s}$.

The number of frame and time of droplet spreading on the superhydrophobic surface are given under the pictures (Figure 3). It is observed that after liquid splashing ( $\mathrm{t}=0.523$ second), water congregates back in droplet, and it oscillates. Then droplet returns to an equilibrium state.

The work was held within the research state assignment "Science" №13.1339.2014/K (Code of Federal Target Scientific and Technical Program 2.1410.2014).

\section{References}

1. S.Y. Misyura, V.E. Nakoryakov, S.L. Elistratov, Int. J. Heat Mass Transfer 55, 6609 (2012)

2. D. Attinger, Z. Zhao, D. Poulikakos, Heat Mass Transfer 122, 544 (2000)

3. P. Calvert, Chem. Mater. 13, 3299 (2001)

4. G. Li; S. M. Flores, C. Vavilala, et.al. Langmuir 25, 13438 (2009)

5. S.S. Sazhin, T. Kristyadi, W.A. Abdelghaffar and M.R. Heikal, Fuel 85, 1613 (2006)

6. C. Dorrer, J. Rühe, Soft Matter 5, 51 (2009)

7. J. Zimmermann, F. A. Reifler, G. Fortunato, L.-C. Gerhardt, S. Seeger, Adv. Funct. Mater. 18, 3662 (2008)

8. X. Gao, X. Yan, X, Yao, L. Xu, K. Zhang, J.-Y. Zhang, Adv. Mater. 19, 2213 (2007)

9. L. Cao, A. K. Jones, V. K. Sikka, J. Wu, D. Gao, Langmuir 25, 12444 (2009)

10. N. J. Shirtcliffe, G. McHale, M. I. Newton, Y. Zhang, ACS Appl Mater Inter 1, 1316 (2009)

11. D. Kwok, R. Lin, M. Mui, A. Neumann, Colloids Surf., A 116, 63 (1996)

12. C. L. Moraila-Martinez, F. J. Montes Ruiz-Cabello, M. A. Cabrerizo-Vhlchez, M. A. Rodrhguez Valverde, Colloids Surf., A 404, 63 (2012)

13. O.A. Kabov, D.V. Zaitsev, Doklady Akademii Nauk 451, 37 (2013)

14. E. Orlova, G. Kuznetsov and D. Feoktistov, EPJ Web of Conferences 76, 012039 (2014)

15. E.G. Orlova, G. V. Kuznetsov, D. V. Feoktistov, EPJ Web of Conferences 82, 01053 (2015) 